\title{
Preparation of binary nanofluid with heat transfer additives by particle surface functionalisation
}

\author{
Umar Aliyu Muhammad ${ }^{1}\left[\right.$ Debabratta Bhattacharyya ${ }^{1} \cdot$ Jose Louis Endrino $^{2} \cdot$ Sonia Fereres $^{3}$
}

Received: 29 April 2021 / Accepted: 18 June 2021 / Published online: 6 August 2021

(c) The Author(s) 2021

\begin{abstract}
Current binary nanofluid synthesis methods with heat transfer additives lack an understanding of the chemistry of the nanoparticle-additive-base fluid interaction, which plays a significant role in the adsorption of the surfactant on the nanoparticle surface. Consequently, this leads to the formation of aggregates within the nanofluid after a couple of days, affecting the stability of the colloidal suspension. Here, a lithium bromide-alumina salt-based nanofluid is proposed following a newly developed synthesis method including particle surface functionalisation. The new procedure developed allows the initial preparation of the nanoparticles with the surfactant as the first step (surface functionalisation) and then the preparation of the base fluid with a dispersion stabilising agent (Gum Arabic) separately. This is then followed by the dispersion of the prepared alumina nanoparticles into the base fluid, by stirring and ultrasonication to produce the final nanofluid, lithium bromide-water ( $\mathrm{LiBr}-\mathrm{H} 2 \mathrm{O}$ )-alumina nanofluid. Until now, proper procedures have not been reported for the nanofluid synthesis combining surfactant and dispersant and the chemistry of nanoparticles-surfactant-base fluid interaction, which was thoroughly investigated in the new approach. The fluid prepared by both the conventional and new procedures was characterised and analysed simultaneously. A thermal conductivity enhancement of $3 \%$ was achieved by using the surface functionalisation method, with greater particle concentration distribution (number of particles in suspension) of $22.7 \%$ over the conventional procedure. It also achieved a 5\% decrease in dynamic viscosity. On the other hand, a Mouromtseff number value between 0.7 and 1.8 was obtained for the fluid at $293 \mathrm{~K}$ and $373 \mathrm{~K}$ temperature range, indicating a strong heat transfer capability. It was apparent from the particle size and concentration distribution analysis conducted that this procedure produced a more stable nanofluid with a high distribution of nanoparticles within the fluid. This allows high improvement of thermal properties of the fluid.
\end{abstract}

Keywords Heat transfer additives $\cdot$ Dynamic viscosity $\cdot \mathrm{LiBr} / \mathrm{H} 2 \mathrm{O}-\mathrm{Al} 2 \mathrm{O} 3$ nanofluid $\cdot$ Mouromtseff number $\cdot$ Particle distribution . Thermal conductivity

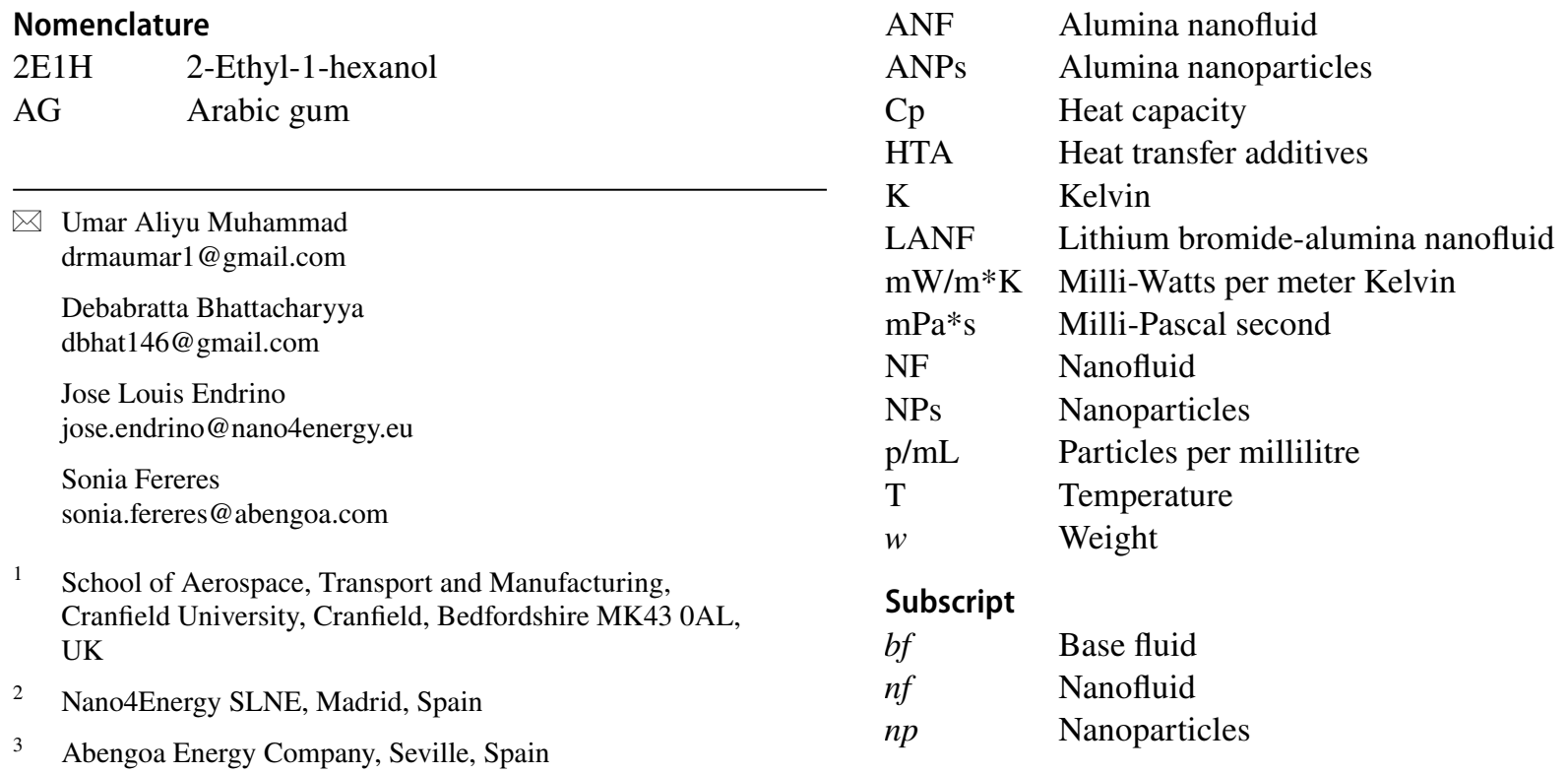




\section{Greek \\ $\rho \quad$ Density \\ $\lambda \quad$ Thermal conductivity \\ $\mu \quad$ Dynamic viscosity}

\section{Introduction}

Absorption refrigeration systems are the focus of a renewed interest because they can be easily adapted to include renewable energy sources of heat (biomass, waste heat, solar, etc.). The working fluid of choice for absorption refrigeration systems is an aqueous LiBr solution, because it is not toxic, and it has a high enthalpy of vaporisation. It can be modified as heat transfer fluid with enhanced thermal conductivity by the dispersion of nanoparticles. This binary nanofluid $\mathrm{H}_{2} \mathrm{O} / \mathrm{LiBr}-\mathrm{Al}_{2} \mathrm{O}_{3}$ undergoes vaporisation between 346 and $368 \mathrm{~K}$, which makes it suitable for use in vapour generation and reabsorption systems. However, obtaining a stable nanofluid through conventional synthesis methods is extremely challenging. Recently, renewable energy systems particularly solar energy have gained great attention as the world embrace clean energy sources. High operating temperature associated with solar thermal systems affects their efficiency immensely [1]. Nanofluids are currently becoming increasingly accepted for use in PVT and other thermal energy systems. Dispersion of nanoparticles improves the thermal conductivity of the base fluid [1,2] and the performance of solar collectors [1]. Sheikholeslami et al. revealed that alumina nanofluid makes up $24 \%$ of nanofluids utilised in flat plate solar collectors [1] and this provides $29.9 \%$ enhancement in performance with $0.2 \mathrm{wt}$. \% of alumina. In addition, the effect of $0.03 \%$ of alumina dispersed in water for similar application for enhanced heat transfer was studied [3]. The presence of alumina in the base fluid was reported to have a significant impact on exergy loss reduction in solar flat plate collectors [3]. An empirical study was also done by Said et al. [4] on the effect of pH stability, volume fraction, nanoparticle size and ultrasonication time of alumina/ water nanofluid for enhancement of thermal efficiency in solar flat plate collectors [5]. A thermal efficiency enhancement of $76 \%$ was reported for alumina/water nanofluid in solar flat plate collector by Sundar et al. [6]. An exergy loss reduction of about $9 \%$ was reported along $9 \%$ enhancement of convective flow due to hybrid nanoparticle dispersion in water by Sheikholeslami and Farshad [7], which intensified the thermal behaviour of the system.

Solar-driven absorption refrigeration systems are an important technology for the current high demand for electricity, space cooling, residential heating and reduction in $\mathrm{CO} 2$ emissions. Meeting this increasing electricity demand needs improvement of the system technology, particularly the absorber and generator [8-10]. Improving the working fluid characteristics is key to optimise both the absorber and generator. Salt-based binary nanofluids can be utilised in an absorption heat transfer system based on their high affinity for water vapour. Lee et al. [11] investigated the effect of both surfactant and nanoparticles within a binary nanofluid containing water $/ \mathrm{LiBr}-\mathrm{Al}_{2} \mathrm{O}_{3}$ in a falling film absorber. Vapour absorption rate can be enhanced significantly with heat transfer rate by the addition of 2-ethyl-1-hexanol. Lee et al. [11] used $0.01 \mathrm{wt} . \%$ alumina in $55 \mathrm{wt} \% \mathrm{LiBr}$ solution and $150 \mathrm{ppm}$ of 2-ethyl-1-hexanol. They obtained $77 \%$ and $19 \%$ enhancement of vapour absorption rate and heat transfer rate respectively. The binary nanofluid proved to be a promising absorption heat transfer fluid. However, they did not present a synthesis procedure for the special nanofluid. The dispersion of nanoparticles into aqueous $\mathrm{LiBr}$ solution has been reported to show no enhancement in vapour absorption rate [12], which confirms that Brownian motion of nanoparticles has little or no impact on the mass transfer of the fluid [12].

A hybrid nanofluid GNP-Ag/water in concentrations of $0.04 \mathrm{wt} \%$ and $0.1 \mathrm{wt} \%$ was used as working fluid in a shell and tube heat exchanger by Alazwari and Safaei [13], showing high viscosity with an enhanced Nusselt number $(\mathrm{Nu})$ and heat transfer coefficient of the system. A novel methodology for predicting the thermo-physical properties of the hybrid nanofluid $\mathrm{TiO}_{2}-\mathrm{ZnO}$-ethylene glycol was developed by Tian et al. [14] using the support vector machine (SVM) method. The new method could accurately predict the thermo-physical properties of a non-Newtonian hybrid nanofluid [14]. Karimipour et al. [15] studied support vector regression (SVR) and artificial neural network (ANN) non-linear regression models for a hybrid nanofluid of MWCNT-CuO/water to predict its thermal conductivity with nanoparticles, varying particle volume fraction and temperature. The results revealed that SVR generalisation was a more suitable regression model for the thermal conductivity prediction of hybrid nanofluids under similar conditions [15]. Another predictive correlation was developed by Afrand et al. [16] to predict the dynamic viscosity of a hybrid nano-lubricant MWCNTs- $\mathrm{SiO}_{2} / \mathrm{AE} 40$ through an optimal artificial neural network. The correlation, which was a function of temperature and nanoparticle volume fraction, proved to be more accurate with just $1.5 \%$ deviation than empirical correlation with up to $4 \%$ deviation when compared to experimental data. Thermal conductivity enhancement can also be predicted by means of ANN and curve fitting correlations [17]. However, the findings by Safaei et al. [17] revealed that using ANN has a better accuracy when determining $\mathrm{ZnO}-\mathrm{TiO} 2 / \mathrm{EG}$ hybrid nanofluid thermal conductivity enhancement. The effects Brownian motion, heat fluxes, bulk mean nanoparticle volume fraction on the heat transfer rate of $\mathrm{Al} 2 \mathrm{O} 3 /$ water nanofluid were studied by Malvandi et al. [18]. With lower heat flux, it was reported 
that nanoparticles have tendency to assemble around the walls [18]. Hence, it shows a non-uniform distribution of thermal conductivity and dynamic viscosity across the nanofluid, although applying a magnetic field has been reported to have a negative effect on the performance of nanoparticles in suspension [18], depending on the particle characteristics. However, nanoparticle migration has a significant impact on the thermo-physical properties and the rheological behaviour of nanofluids [18]. According to Akbari et al. [19], the properties of nanofluids can be determined from the properties of both the base fluid (water) and that of the nanoparticles $\left(\mathrm{Al}_{2} \mathrm{O}_{3}\right)$. Investigation into the heat transfer rate of laminar flow of $0,2 \%$ and $4 \% \mathrm{Al}_{2} \mathrm{O}_{3}$ /water nanofluid revealed an enhancement of heat transfer rate with increasing volume fraction of nanoparticles [19].

Karimipour et al. [20] synthesised $\mathrm{CuFe} 2 \mathrm{O} 4-\mathrm{SiO} 2 /$ waterethylene glycol by dispersing $\mathrm{CuFe} 2 \mathrm{O} 4 / \mathrm{SiO} 2$ nanocomposites into water/ethylene glycol (60:40). Magnetic stirring for $2 \mathrm{~h} 30 \mathrm{~min}$ and then ultrasonic vibration was applied for $2 \mathrm{~h}$ [20] to reduce agglomeration. A new synthesis method for hybrid nanofluids was reported by $\mathrm{H}$. Yarmand et al. [21] through acid functionalisation of graphene nanoplatelets. The method forms a uniform nanocomposite of GNP-Pt (platinum) via chemical reaction of acid-GNP functionalisation without the addition of any surfactant. The resulting nanofluid (GNP-Pt/water) shows significant stability without sedimentation for 22 days [21]. A modified hummer's method can also be used to synthesise graphene oxide-water nanofluids. Graphene oxide is first prepared by the oxidation of graphene flakes prior to their dispersion in water. Nanofluids synthesised with this method showed stability of about 3 months [22], having potential as heat transfer working fluids in thermal energy systems [22]. The synthesis process takes 60 min of continuous magnetic stirring, followed by 40 min of ultrasonic vibration using a 400-W-24$\mathrm{kHz}$ ultrasonicator from Hielscher Company, Germany [22]. In a related study, oleic acid was used as surfactant for surface functionalisation of $\mathrm{Fe}_{3} \mathrm{O}_{4}$ in the preparation of an iron oxide nanofluid in mineral oil [23]. The nanofluid was reported to have a good dispersion stability [23]. Recently, A. Shahsavar et al. [24] also employed a similar method to synthesise a Fe3O4-liquid (concentration of $0.5-3 \%$ and temperature range between 20 and $90{ }^{\circ} \mathrm{C}$ ) paraffin mixture using the two-step method. The iron oxide was dispersed in liquid paraffin-oleic acid mixture to enhance its dispersion stability. In this method, the liquid paraffin and oleic acid were initially mixed and allowed to stir on a magnetic stirrer for $20 \mathrm{~min}$ at $400 \mathrm{rpm}$. This nanofluid was reported to have enhanced thermal conductivity with nanoparticle concentration and temperature increase [24]. Another article [25] presents a two-step procedure for a $\mathrm{ZnO}-\mathrm{MWCNT/engine}$ oil (SAE 10W40) nanofluid preparation with 2-h and 30-min continuous magnetic stirring and $7 \mathrm{~h}$ of ultrasonication. The procedure recommends a 30-min break for every $30 \mathrm{~min}$ of ultrasonication for sample temperature control and an optimum ultrasonication time of $5 \mathrm{~h}$ and $15 \mathrm{~min}$ to produce a stable nanofluid [25]. Hybrid nanofluids were also synthesised by decorating graphene nanoplatelets with silver nanoparticles [26, 27]. Ag (NH3)2OH solution is used to decorate graphene nanoplatelets after functionalisation with acid [27]. A direct mixing of nanoparticles, surfactant and base fluid using the two-step method of nanofluid synthesis was implemented by [28]. The formulation for the preparation of the hybrid ferro-nanofluid is $75 \%\left(\mathrm{Fe}_{2} \mathrm{O}_{3}\right): 25 \%\left(\mathrm{Al}_{2} \mathrm{O}_{3}\right)$, base fluid; distilled water and ethylene glycol/distilled water mixture at 50-50 vol.\% [28] and a surfactant; and SDS and NaDBS. The ultrasonication time was between 60 and $240 \mathrm{~min}$ and the surfactants were found to stabilise the ferronanofluids from the two base fluids [28].

Recent literature [20-28] presents different methods for the synthesis of nanofluids with additives for functionalisation purposes in an attempt to either obtain (a) a stable nanofluid, (b) enhancement in thermal conductivity or (c) improved heat transfer rate. However, the synthesis procedure has not been given adequate attention; rather, researchers have been more concerned with the characterisation methods and techniques of the nanofluid [13-19]. With growing interest in co- and trigeneration systems [29], there is an increasing interest in salt-based working fluid as absorption heat transfer fluids, particularly the traditional $\mathrm{LiBr}$ solution [30]. This paper intends to develop a step-bystep method for preparing binary nanofluids with heat transfer additives. For this purpose, lithium bromide-alumina nanofluid (LANF- $\mathrm{H}_{2} \mathrm{O}$ ) with heat transfer additives (HTA), 2-ehyl-1-hexanol (2E1H) and Gum Arabic (GA) were used. The working fluid is intended to be utilised in concentrated solar absorber tubes for direct vapour generation through the integration of a solar absorber tube of a linear Fresnel collector in a generator section of an absorption machine. The solar absorber tube will act as a vapour separator as well as a super-heater by configuring it with the descending LANF liquid film under evaporation inside an inclined tube.

\section{Synthesis of lithium bromide-alumina nanofluid}

In this work, the two-step method was adopted due to the simplicity of the technique and its cost-effectiveness compared to a one-step method. Figure 1 shows the conventional procedure to prepare a nanofluid containing surfactant used in a two-step method: nanoparticles are mixed directly into the base fluid, this mixture is stirred, surfactant is added and the colloid is ultrasonicated. In contrast to the conventional method, a new preparation procedure using surface

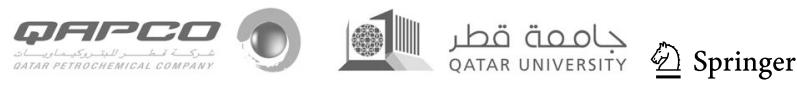


Fig. 1 Schematic of a conventional procedure for binary nanofluid synthesis with a surfactant using a two-step method [31]. Direct mixing with magnetic stirrer at $400 \mathrm{rpm}$ for $2 \mathrm{~h}$, and ultrasonication for up to $7 \mathrm{~h}$ is usual conventional practice. In both cases, temperatures are maintained between 298 and $308 \mathrm{~K}$

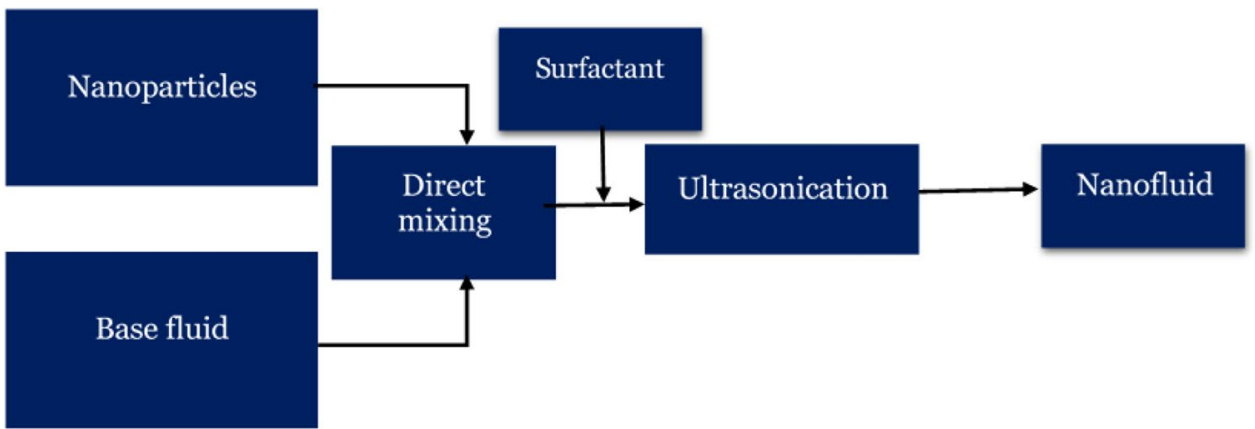

functionalisation method for the nanoparticles prior to mixing them with the base fluid was developed.

For the study, two different heat transfer additives (HTA) were used: Gum Arabic (GA) and 2-ethyl-1-hexanol (2E1H). The GA is used as nanoparticle dispersion stabiliser, while $2 \mathrm{E} 1 \mathrm{H}$ is a surfactant, and is used for nanoparticle surface functionalisation and for surface tension reduction. The synthesis of LiBr-ANF with HTA is also based on a two-step synthesis procedure for nanofluid development and further modified for HTA inclusion and the step-by-step procedure is outlined below:

- Step 1: Reagent preparation. Each reactant (Gum Arabic (GA), $\mathrm{LiBr}$ and alumina nanoparticles (ANPs)) is predried separately for $30 \mathrm{~min}$ on a hot plate set at $373 \mathrm{~K}$ to remove any impurities present in each of the samples. The sample materials were then weighed with a Mettler balance AE-240.

A weight percent of 0.01 of ANPs with 20-nm particle size was used. The concentration of $0.01 \mathrm{wt} \%$ Gum Arabic was also required and $150 \mathrm{ppm}(0.150 \mathrm{~g} / \mathrm{L}$ or $0.015 \%)$ of 2-ethyl-1-hexanol $(2 \mathrm{E} 1 \mathrm{H})$. These concentrations are considered the best recipe for the particular nanofluid stability from experimental results according to Lee et al. [11].

- Step 2: Sample preparation. Three different samples were prepared: LANF without heat transfer additives (HTA); LANF with HTA prepared using the conven- tional method presented in Fig. 1; and LANF with HTA prepared through surface functionalisation method suggested in this article. It is necessary to include the first sample LANF without HTA to serve as a baseline study for understanding the effects of HTA addition in the other two samples. Furthermore, the samples' comparative analysis can help assess whether or not there is any benefit with the new approach of surface functionalisation. The first sample (S1, Table 1) was set up by simply dispersing alumina nanoparticles (ANPs) into the base fluid (aqueous lithium bromide $55 \mathrm{wt} \%$ solution) to the ANPs. The second sample (S2, Table 1) LANF with HTA prepared using the conventional method was set up by directly adding the ANPs to the base fluid first (like the first sample), then followed by the addition of GA and finally, introducing the surfactant $(2 \mathrm{E} 1 \mathrm{H})$ through the conventional method described in Fig. 1. The third sample (S3, Table 1) was synthesised differently, where the ANPs were first mixed with the surfactant $(2 \mathrm{E} 1 \mathrm{H})$ and allowed to stand for about 15-20 min. On the other hand, the base fluid, $\mathrm{H} 2 \mathrm{O} / \mathrm{LiBr}$ solution, was added to the $\mathrm{AG}$ powder and stirred until it completely dissolved; however, no timing is required for the dissolution process. Then, the base fluid was added to the surface functionalised ANPs. Hence, all three samples were then ready for the next step, the synthesis process.

- Step 3: Synthesis process. This is usually the last step in nanofluid preparation. All three samples $(\mathrm{S} 1, \mathrm{~S} 2, \mathrm{~S} 3$

Table 1 Samples prepared as part of this study to analyse the effect of surface functionalisation of the NP prior to dispersing them in the base fluid

\begin{tabular}{|c|c|c|c|}
\hline \multicolumn{2}{|c|}{ Sample description } & \multirow{2}{*}{$\begin{array}{l}\text { Composition } \\
\mathrm{LiBr} / \mathrm{H} 20+\mathrm{A} 12 \mathrm{O} 3 \mathrm{NP}\end{array}$} & \multirow{2}{*}{$\begin{array}{l}\text { When is } 2 \mathrm{E} 1 \mathrm{H} \text { added? } \\
\text { N/A }\end{array}$} \\
\hline S1 & Reference nanofluid no HTA & & \\
\hline $\mathrm{S} 2$ & Nanofluid with HTA conventional synthesis & $\mathrm{LiBr} / \mathrm{H} 20+\mathrm{Al} 2 \mathrm{O} 3 \mathrm{NP}+\mathrm{GA}+2 \mathrm{E} 1 \mathrm{H}$ & $\begin{array}{l}\text { With GA, after the } \\
\mathrm{NP} \text { are mixed in the } \\
\text { base fluid }\end{array}$ \\
\hline S3 & Nanofluid with HTA with surface functionalisation & $\mathrm{LiBr} / \mathrm{H} 2 \mathrm{O}+\mathrm{A} 12 \mathrm{O} 3 \mathrm{NP}+\mathrm{GA}+2 \mathrm{E} 1 \mathrm{H}$ & $\begin{array}{l}2 \mathrm{E} 1 \mathrm{H} \text { is added to dry } \\
\text { ANP, prior to mix- } \\
\text { ing with base fluid }\end{array}$ \\
\hline
\end{tabular}


with composition and characteristics shown in Table 1) were allowed to stir using a magnetic stirrer for $30 \mathrm{~min}$, which was followed by ultrasonication for $150 \mathrm{~min}$ $(2.5 \mathrm{~h})$. This gives a slightly viscous but stable nanofluid. It has been reported that the viscosity is affected by addition of ANPs and HTA, and not by the ultrasonication time as supported by Mahbubul et al. [32].

The ultrasonic vibration process allows the dispersion of the ANPs intensively in order to minimise the degree of agglomeration according to Lee et al. [33], Wang et al. [34] and Eastman et al. [35] in their $\mathrm{H}_{2} \mathrm{O}$ /alumina nanofluid (ANF) preparations. While $\mathrm{pH}$ control method is used to obtain nanoparticle stability [36], other techniques use surfactants to achieve stability in nanofluids. These techniques allow the modification of the surface chemistry of dispersed nanoparticles to avoid formation of clusters. Surfactants must be selected based on the properties of both the base fluid and nanoparticles. The schematic of detailed LANF new synthesis procedure (the surface functionalisation method) with HTA is outlined below (Fig. 2).
In the nanoparticle preparation, the surfactant, $2 \mathrm{E} 1 \mathrm{H}$, was directly added to the ANPs to modify their surface chemistry as earlier mentioned for surface functionalisation method. This is in contrast to the conventional method, where $2 \mathrm{E} 1 \mathrm{H}$ was added after the particles were mixed with the base fluid and GA. For a compound to be a surfactant, it should essentially possess a characteristic of surface activity, which is exhibited by $2 \mathrm{E} 1 \mathrm{H}$. This enables the addition of a small amount of the compound into a liquid or onto a solid to get adsorb at the surface or solid-liquid interface respectively. Hence, it facilitates the reduction of interfacial or surface excess free energy, which causes high surface or interfacial tension. Therefore, adding the surfactant over the ANPs would solve the following problems:

- High solid-liquid surface tension-excess free energyinteraction usually experience during direct mixing,

- Longer ultrasonication time of 12 to $24 \mathrm{~h}$ as practice by some researchers $[37,38]$ would no longer be necessary and

- The extent or risk of clustering of NPs.
Fig. 2 Schematic flow chart for a new synthesis procedure of nanofluid with HTA
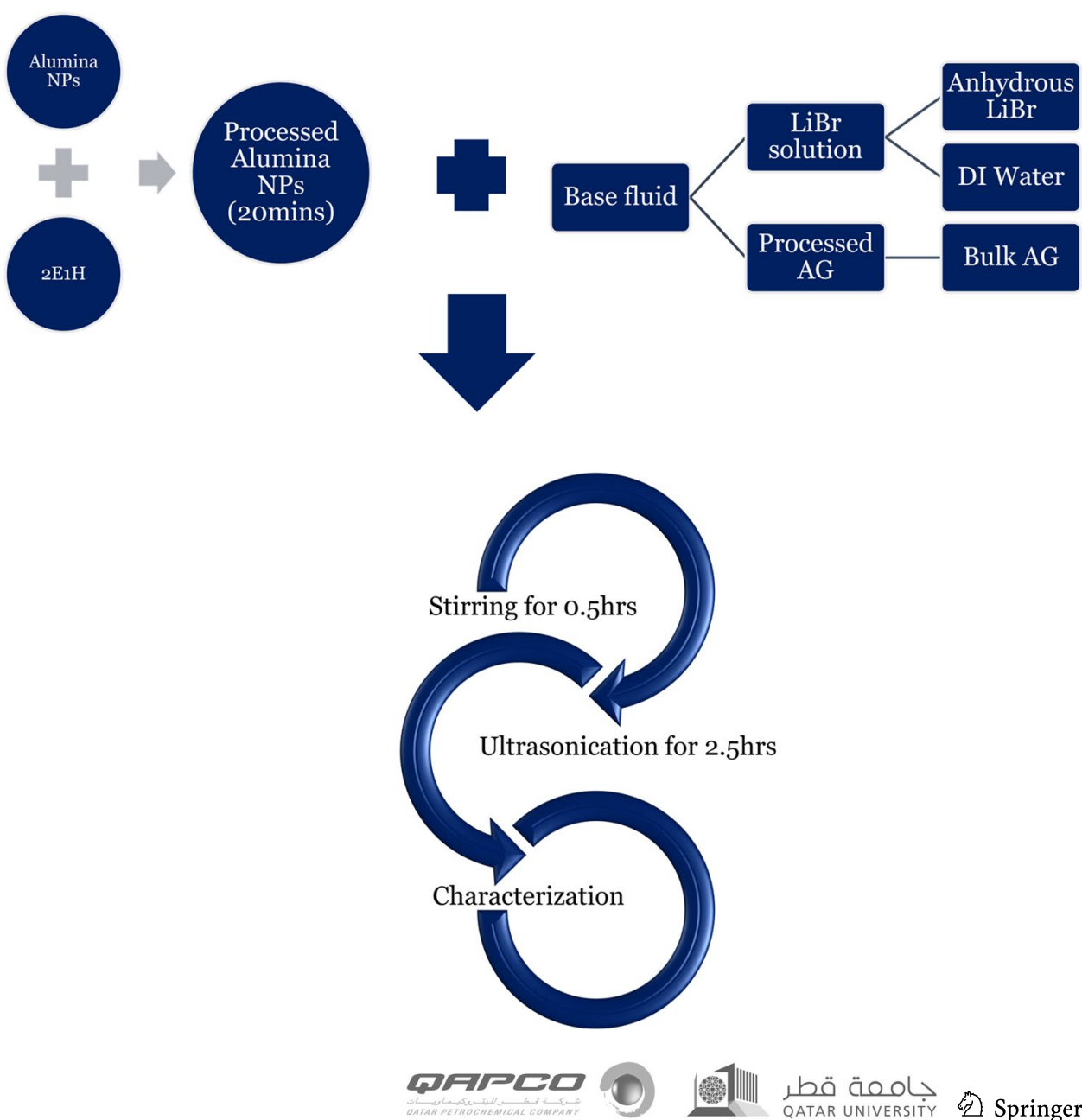
Fig. 3 In sample S1 nanofluid without HTA, some nanoparticles settle down, while in sample S2 and S3 nanofluids with HTA but prepared by different methods, nanoparticles were completely in suspension no particles seen settling after $12 \mathrm{~h}$
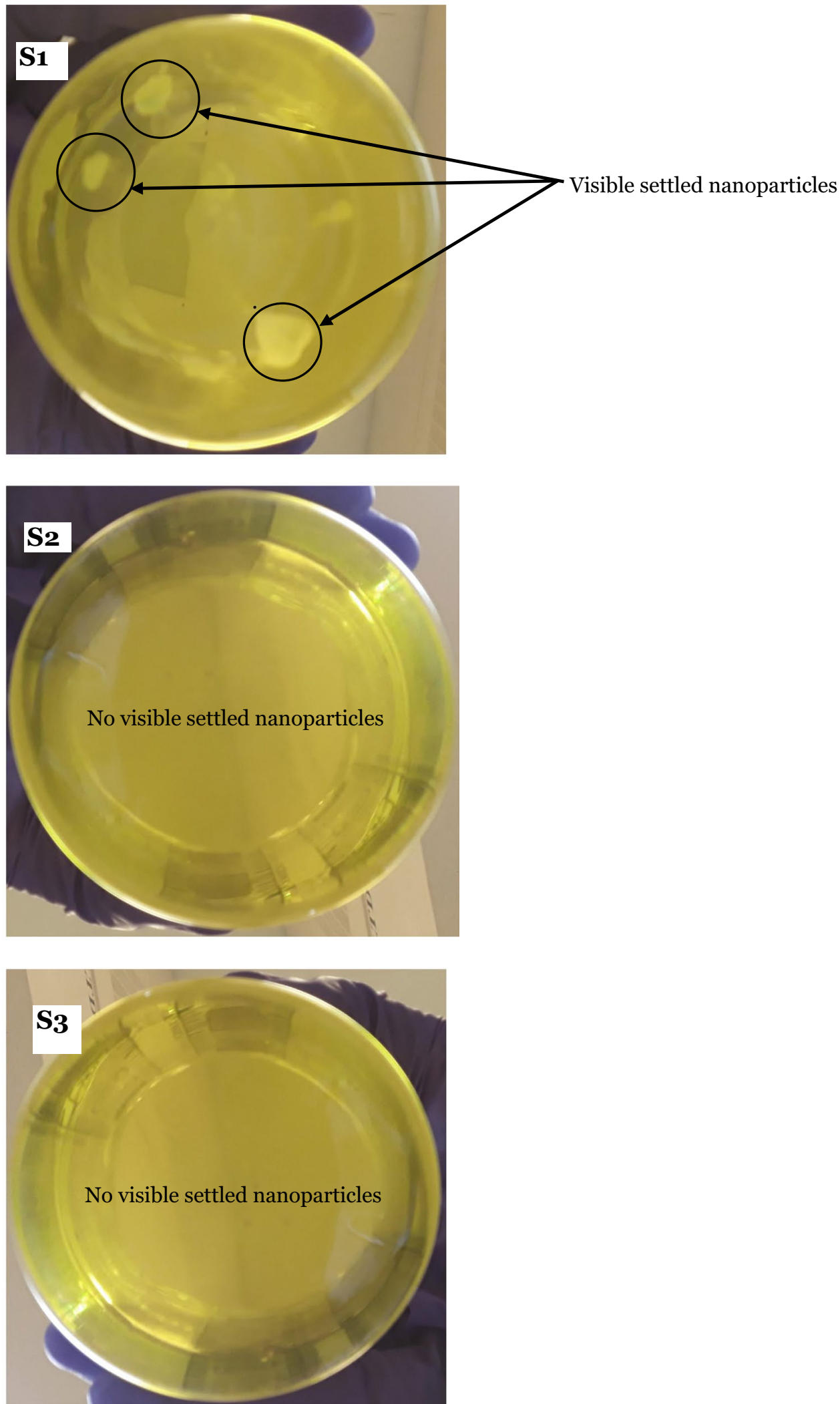

However, if the surfactant were introduced after NPs dispersion in the base fluid, the adsorption of the surfactant

would be hindered at $\mathrm{LiBr}$ solution-ANPs interface, which is expected to influence the adsorption mechanism. This has 
Fig. 4 NanoSight NS300 particle size analyser internal mechanism [39]

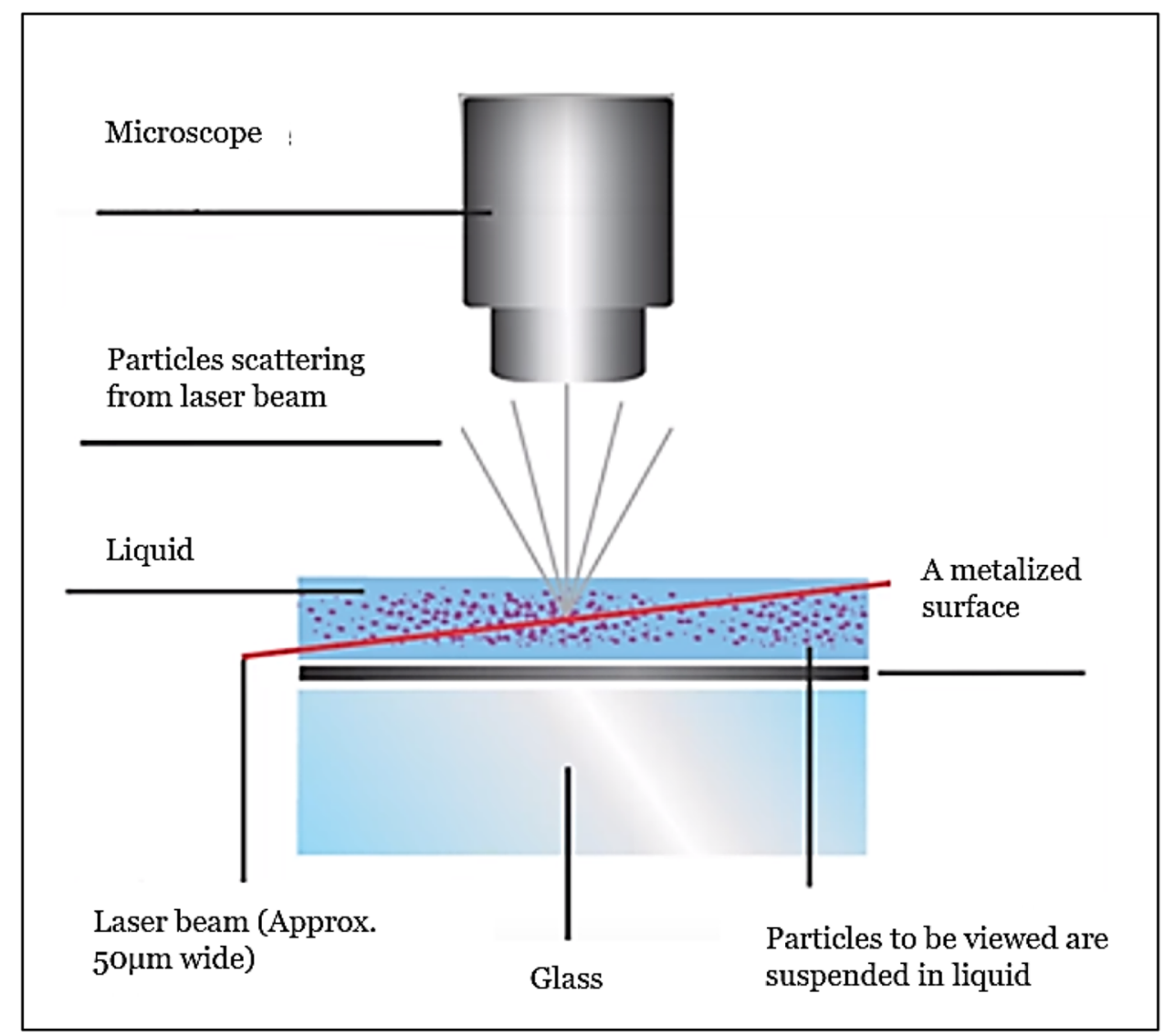

an adverse effect subsequently on the heat transfer characteristics of the fluid. Some critical challenges include the following:

- nanoparticle surface polarity and charge

- 2E1H molecular structure

- Characteristic of the LiBr solution, such as its high pH value, solution temperature and the presence of gum Arabic.

All these factors would further influence the chemistry and dynamics of the adsorption process of $2 \mathrm{E} 1 \mathrm{H}$ on ANPs when already dispersed in the base fluid.

Figure 3 presents images of what was observed after the preparation of LANF with and without the HTA. Particle agglomeration attributed to high surface energy can be seen in Fig. 3 sample S1 below when ANPs were dispersed in LiBr solution without HTA. Agglomeration of particles appears throughout the solution, sedimenting and showing particle instability within the fluid. However, when dispersion stabilising agents, Arabic gum and $2 \mathrm{E} 1 \mathrm{H}$, were used in the synthesis process, the nanofluid was stabilised and no agglomeration could be seen as shown in Fig. 3 samples $\mathrm{S} 2$ and $\mathrm{S} 3$.

\section{Characterisation of LiBr-Al2O3 nanofluid with heat transfer additives}

It is important to remember that the major difference between the conventional method for nanofluid synthesis with HTA and the surface functionalisation method suggested in this article is that nanoparticle surfaces were functionalised with surfactant and allowed to stand for $20 \mathrm{~min}$ at ambient temperature prior to their dispersion in the base fluid. The reason for these conditions is to allow adequate time for surfactant adsorption onto nanoparticles' surface. The base fluid is treated with a stabilising agent, GA, regardless of the nanoparticle treatment (surface functionalisation or not). These HTA could modify the thermal properties of the binary nanofluid. The nanoparticle concentration distribution, dynamic viscosity and thermal conductivity of the samples were experimentally measured; the Mouromtseff number $(M o)$ calculated in an attempt to study the two methods for nanofluid synthesis with HTA.

The three samples prepared were as follows:

1) LANF without HTA = lithium bromide-alumina nanofluid without heat transfer additives

2) $\mathrm{LANF}+\mathrm{HTA}+\mathrm{CM}$ : prepared by conventional method (CM)

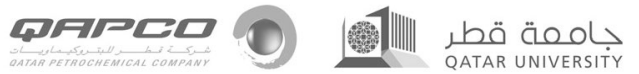




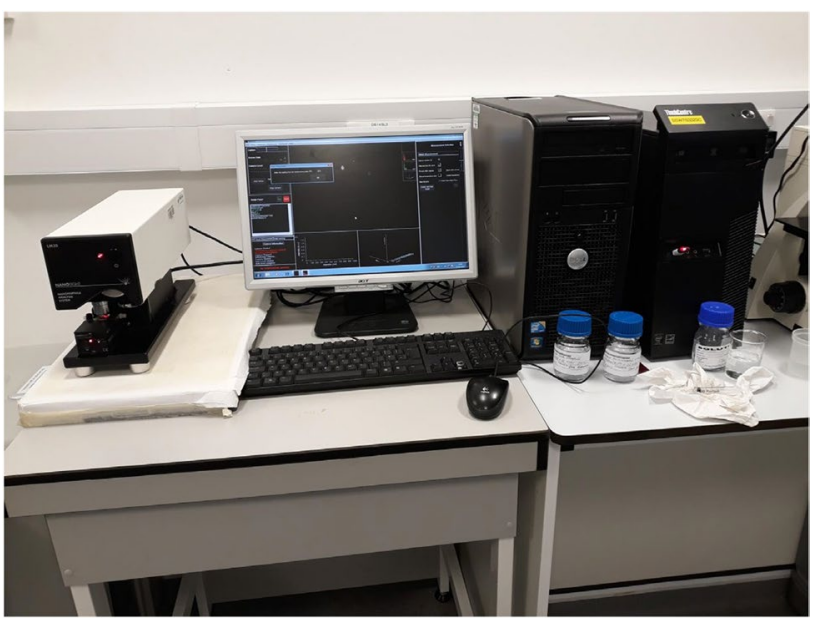

Fig. 5 Image of NanoSight NS300 particle size analyser setup

3) LANF + HTA + SFM: prepared by surface functionalisation method (SFM)

\subsection{Particle size and distribution measurement}

The NanoSight NS300 was used to analyse and characterise the alumina NPs size and concentration distribution. The instrument has the capability of providing further complementary detailed information to that provided by dynamic light scattering (DLS). Two of the unique parameters that can be obtained by nanoparticle tracking analysis are the evaluation of nanoparticle concentration and high-resolution particle size distribution measured on particle-by-particle basics. The size is determined from the Brownian motion of the particles in a solution in which, for a given sample of nanoparticle suspension, the particle tracking was carried out simultaneously. In effect, as each particle is tracked individually, high-resolution number versus size distribution is generated by the measurement unit immediately (Figs. 4 and 5).

Portions of the three samples prepared were used to determine the size and concentration distribution of the ANPs in suspension. The results are shown in Fig. 6 for samples LANF without HTA, LANF + HTA + conventional method $(\mathrm{CM}), \mathrm{LANF}+\mathrm{HTA}+$ surface functionalisation method (SFM) with particles size of $20.1 \mathrm{~nm}, 22.7 \mathrm{~nm}$ and $20.5 \mathrm{~nm}$ and concentration distribution of $17 \mathrm{p} / \mathrm{mL}, 22 \mathrm{p} / \mathrm{mL}$ and $27 \mathrm{p} /$ $\mathrm{mL}$ respectively.

It is clear from the plots that the ANPs were more evenly distributed in suspension when HTA were used and when using the new surface functionalisation method. The presence of a stabilising agent helped to keep more particles in suspension in both samples containing HTA. Surface functionalisation of ANPs with $2 \mathrm{E} 1 \mathrm{H}$ prior to dispersion was responsible for the high ANPs concentration distribution in the new method. The conventional method has less particle size distribution than the SFM, and larger particle size than the other two samples. This is owing to deposition of gum Arabic onto the surface of ANPs during and after mixing, which is expected in the case of the conventional method. This scenario is avoided with the SFM due to the initial surface functionalisation of the ANPs.

\subsection{Thermal conductivity}

The most adapted method for thermal conductivity measurement is the transient hot wire method. This method was reported by [40] to have about $60 \%$ publications utilising the
Fig. 6 Experimental result of particle size and concentration distribution measurement for alumina nanoparticles in the three samples using NanoSight NS300

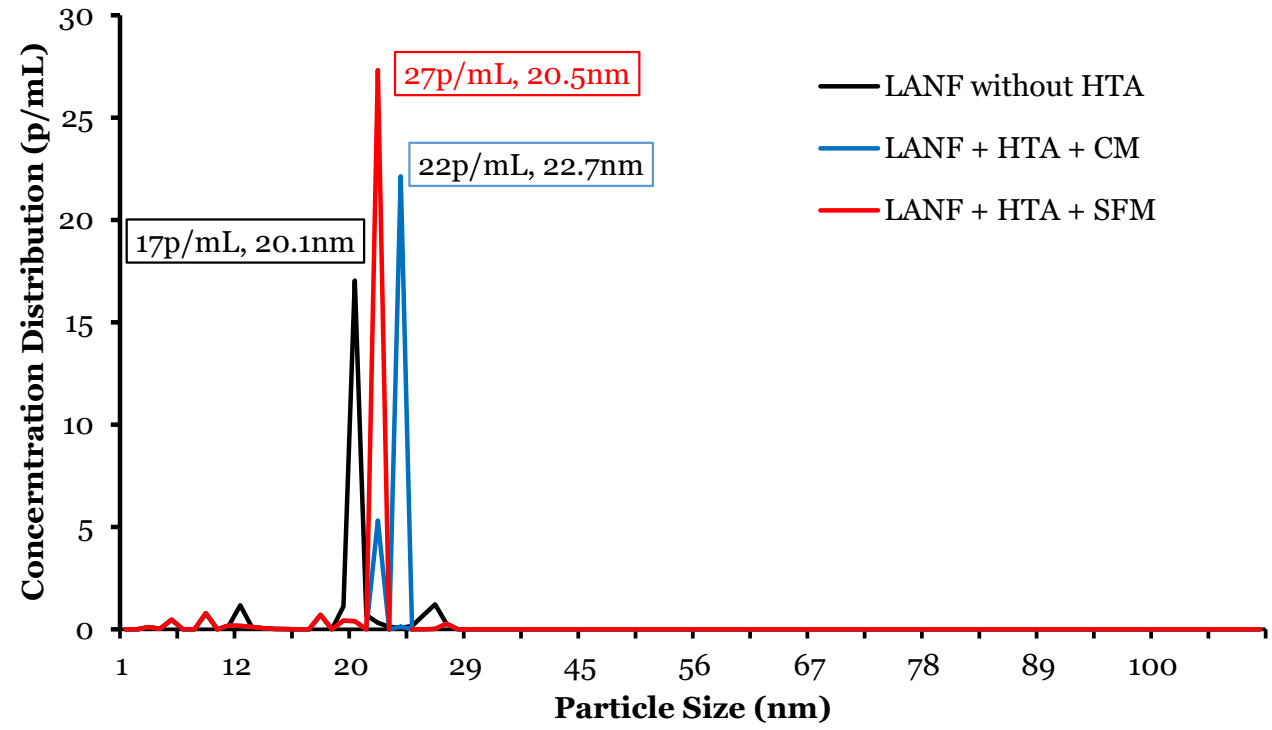


technique. This method is first known as non-steady-state method for determining the thermal conductivity of a liquid across a wide temperature range developed by Stalhane and Pyk [41]. Healy et al. [42] published the corrections to this method and the corresponding theory for validation. This method has two approaches for measuring the thermal conductivity. The one suitable for corrosive nanofluid and liquids such as LANF or even pure $\mathrm{LiBr}$ solution is called the transient short wire. However, it is also used for other types of nanofluid [43]. The other approach is called the liquid metal transient hot wire. In the latter, mercury in a glass capillary is suspended in the nanofluid as it conducts thermally through buoyancy. Mashali et al. [40] presented the complete description of the setup.

According to Bouguerra et al. [38], the inappropriate technique previously used for measuring thermal conductivity of nanofluid is responsible for the long-standing ambiguity in assessing the contribution of nanoparticles to the thermal conductivity enhancement of nanofluids [38]. They also suggested $\mathrm{pH}$ and surfactant have greater influence on the thermal conductivity enhancement [36]. It is necessary to stabilise $\mathrm{pH}$ of the suspension to provide a robust enhancement along with surfactant. In this work, the transient hot wire technique had been used for determining thermal conductivity with appropriate procedure as suggested by Bouguerra et al. [38, 36

].

The transient hotwire method technique allows measuring thermal conductivity of nanofluid over a range of temperature by raising the temperature of the metal wire. In this case, the thermal conductivity measurements of LANF samples were pursued using THW method to investigate the effect of synthesis procedure and HTA in binary nanofluid on its thermal characteristics. It should be noted that the sample preparation needs to be monitored carefully in adding and maintaining the concentration of each constituent. The metal wire was immersed in each sample, which heats up the nanofluid and also serves as a resistance thermometer.

Thermal conductivity of base fluid is usually low, but metallic oxide nanopowder such as alumina is much higher and by dispersing it into a given base fluid results in an increase in thermal conduction of the corresponding nanofluid. The

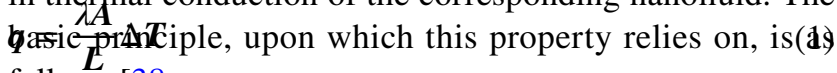
follows [38

where $A\left(\mathrm{~m}^{2}\right)$ is the area in which heat $q$ is applied with a temperature difference of $\Delta T(\mathrm{~K})$ across a distance $L(\mathrm{~m})$ of a material with thermal conductivity $\lambda(\mathrm{W} / \mathrm{mK})$. The thermal conductivity can also be presented as effective thermal conductivity. This is the ratio of thermal conductivity of the nanofluid to that of the base fluid as shown in Eq. 3 [38, 38 $\lambda_{\text {enhancement }}(\%)=\frac{\lambda_{n f}-\lambda_{b f}}{\lambda_{b f}} \times 100$

$\lambda_{\text {effective }}=\frac{\lambda_{n f}}{\lambda_{b f}}$

where $\lambda$ is thermal conductivity, $\lambda_{n f}$ is the thermal conductivity of nanofluid and $\lambda_{b f}$ is the thermal conductivity of the base fluid.

In spite of the dispersion stability provided by the gum Arabic, addition of surfactant is required to improve thermal conductivity of nanofluid. This can be explained by chemical nature of a surfactant, which enables it to modify the surface chemistry of the nanoparticles and their interaction with the base fluid. However, the surfactant partially solubilises to liberate hydroxide ions, $\mathrm{OH}^{-}$thereby increasing the $\mathrm{pH}$ value of the nanofluid as presented in Table 1. On the other hand, gum Arabic, a sugar polymer, with a $\mathrm{pH}$ value in the range of 4.5 to 5.5 [44] provides an excellent dispersion stabilising, emulsifying and suspension characteristics in the nanofluid. It also helps in stabilising the $\mathrm{pH}$ of the nanofluid. In addition, it was observed that addition of surfactant alone does not facilitate the improvement of both thermal conductivity and stability, whereas stabilising the $\mathrm{pH}$ of the nanofluid does play that significant role as reported by Bouguerra et al. [36], which is provided by the gum Arabic (Table 2).

In Figs. 7 and 8, the measured effect of temperature on thermal conductivity is shown for comparative study. In general, the thermal conductivity increases with increasing temperature is well known. Thermal conductivity of a nanofluid is strongly influenced by temperature as explained by [45]. However, the influence of additives and synthesis procedure had been assessed to tailor the performance of the different nanofluids. The addition of HTA has improved the thermal behaviour of the nanofluid when compared to the sample without HTA.

The analysis of the results presented in Fig. 7, reveals that in all cases the SFM sample has a higher thermal conductivity. It has been suggested that this increase in thermal conductivity can be attributed mainly to the Brownian motion of the dispersed ANPs [46]. As the temperature increases, the Brownian motion of the particles also increases rapidly,

Table $2 \mathrm{pH}$ data for different samples, measured using a digital $\mathrm{pH}$ meter

\begin{tabular}{ll}
\hline Samples & pH values \\
\hline LANF without HTA & $9.3 \pm 0.1$ \\
LANF + HTA + CM & $9.8 \pm 0.1$ \\
LANF + HTA + SFM & $9.7 \pm 0.1$ \\
Manufacturer & 9.4 \\
\hline
\end{tabular}


Fig. 7 Experimental results of thermal conductivity of samples against temperature $(\mathrm{K})$

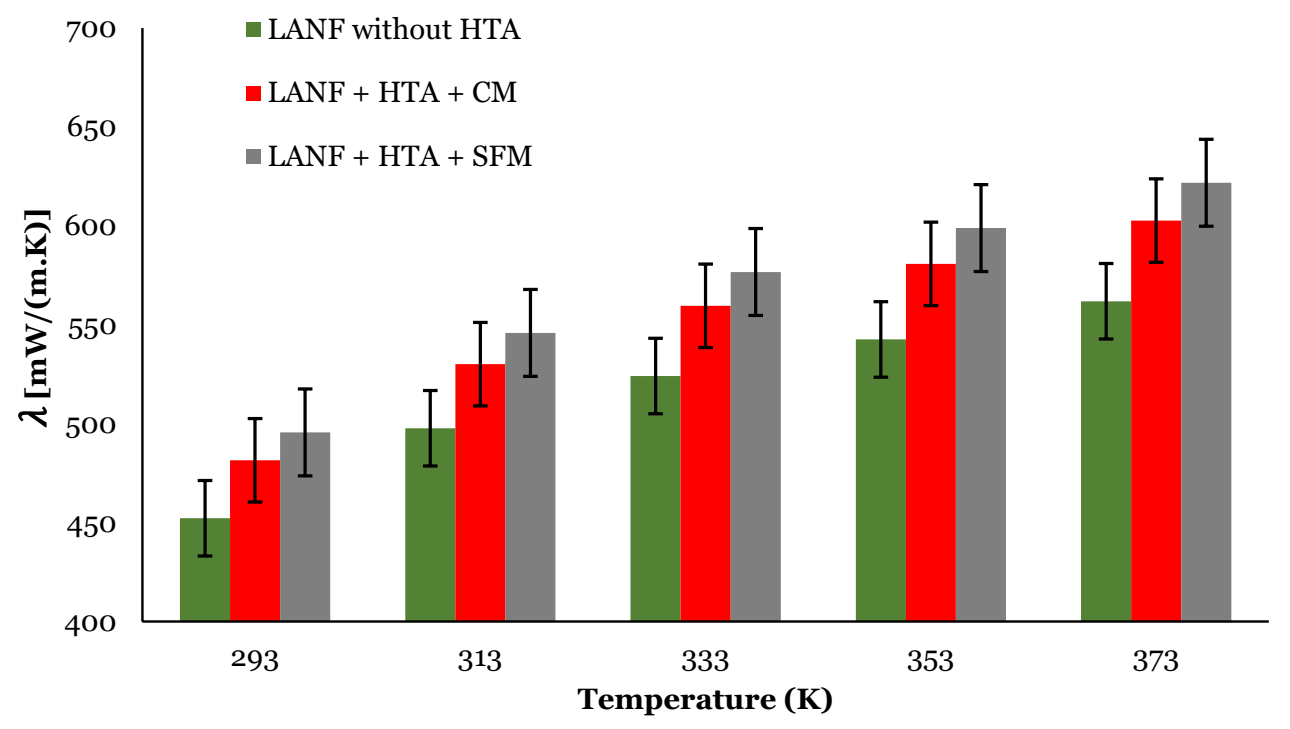

thereby enhancing further the thermal conductivity. On the contrary, Jabbari et al. [46] reported that the effects of Brownian motion of nanoparticles on thermal conductivity had revealed that Brownian motion has apparently no influence on thermal conductivity of nanofluid. Nevertheless, Philip and Shima [47] provided similar results, supporting these findings. Other reasons for an increase in thermal conductivity with operating temperature are associated with a large surface area of the ANPs and increased interfacial thermal resistance at $\mathrm{LiBr}$ solution-ANP interface.

The most interesting point is that, in both Figs. 7 and 8, the SFM sample presents the highest effective and thermal conductivity of the three samples, hence a higher thermal conductivity enhancement. This is due to the large particle concentration distribution as a result of surface functionalisation of ANPs.
Thermal conductivity enhancement presented in Fig. 9 shows enhancements due to the addition of HTA and surface functionalisation of ANPs. An average thermal conductivity enhancement of $10 \%$ and $6.8 \%$ was observed when using SFM and conventional method respectively. This is in comparison to the thermal conductivity of LANF without HTA sample. Thus, an enhancement of $3 \%$ was recorded using SFM over conventional method of nanofluid preparation with HTA, which explains the significant impact the new synthesis procedure has made on thermal conductivity of the fluid.

\subsubsection{Dynamic viscosity}

A rotational viscometer was used to determine the viscosity of the fluid samples. The measurement is done by
Fig. 8 Calculated results of effective thermal conductivity of samples against temperature (K) using Eq. 1

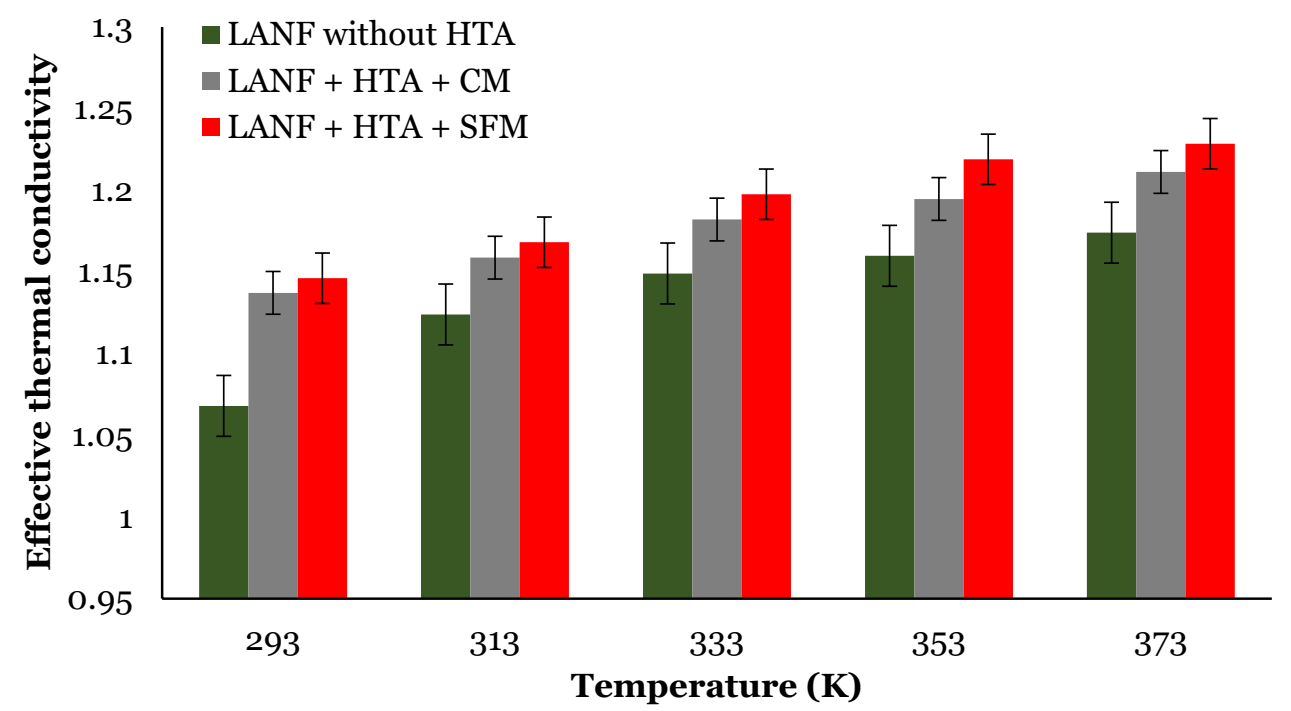


Fig. 9 Calculated results of thermal conductivity enhancement (\%) of samples against temperature $(\mathrm{K})$. Where En$\mathrm{HTA}+\mathrm{SF}$ is enhancement due to HTA addition and surface functionalisation; En-HTA is enhancement due to HTA addition; and En-SF is enhancement due to surface functionalisation

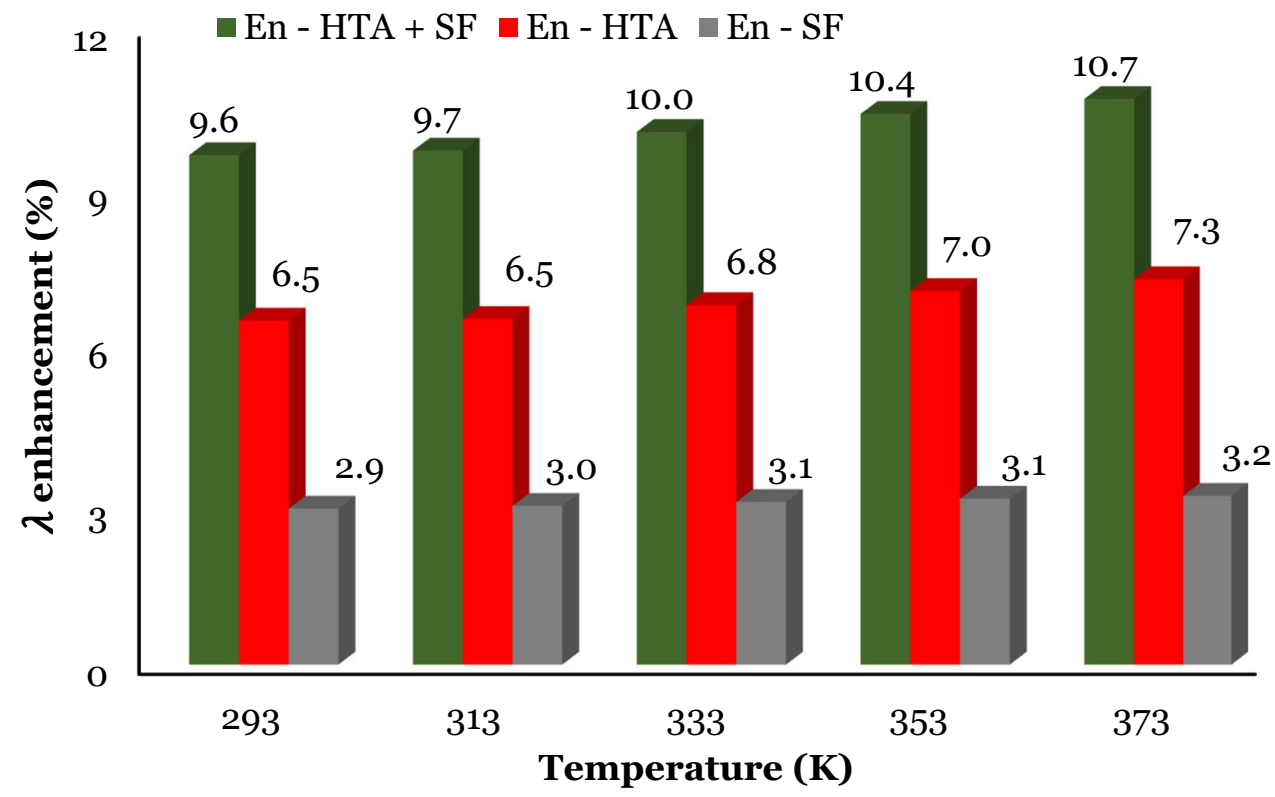

submerging the spindle in the fluid sample, which allows it to sense the torque necessary to revolve it at a constant speed. It is a well-known phenomenon that viscous drag around the spindle is proportional to the torque. This device can be used to measure the viscosity of Newtonian and nonNewtonian fluids since the rate of shear is constant.

The ultrasonication of a base fluid with dispersed nanoparticles usually results in a slight increase in viscosity of the corresponding nanofluid with less than $1 \%$. The introduction of gum Arabic into the LANF resulted in increase in viscosity. This is due to its emulsifying property and also size transformation of nanoparticles it has caused in the final fluid mixture.

The dynamic viscosity illustrated in Fig. 10 shows the effect of temperature on viscosity of the three samples at a constant shear rate $2 \mathrm{~S}^{-1}$. Addition of nanoparticles can increase viscosity, the extent of which depends on the volume fraction and particle size used. According to $\mathrm{Lu}$ and Fan [48], Rudyak and Krasnolutskii [49, 50] and Lou and Yang [51], both viscosity and thermal conductivity of nanofluid decrease with increasing particle size. In addition, Lu and Fan [48, 52], Rudyak and Krasnolutskii [49, 50, 53-55] and Lou and Yang [51] had reported that shear viscosity of nanofluid increases due to an increase in volume fraction of nanoparticles. In this case, an increase in viscosity due to nanoparticles as observed at low temperature gradually disappears as operating temperature was increased. At elevated temperature, this restriction to flow is substantially removed and the nanofluid is allowed to flow more smoothly-with negligible effect—as the original base fluid would behave.
Fig. 10 Experimental results of dynamic viscosity of samples against temperature $(\mathrm{K})$ at $2 \mathrm{~S}^{-1}$ shear rate and $\pm 1 \%$ standard error

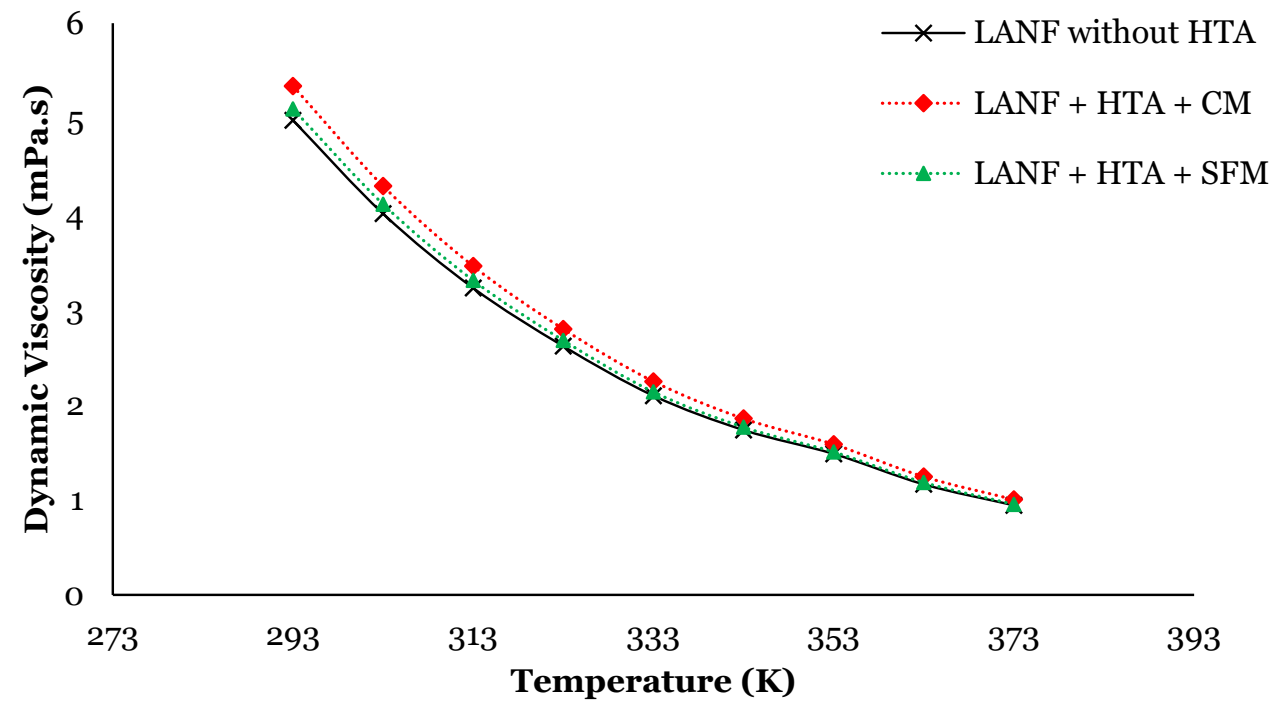


Gum Arabic is a polysaccharide with high molecular weight that is primarily used as hydrocolloid in food and beverages industries. It contains up to $50 \%$ galactose and $16 \%$ protein [56]. The binding or hydrocolloidal property of this substance makes it more viscous in nature. In nanofluid mixture, the deposition of both protein and starch layers of gum Arabic on ANPs, slightly increases the particle size and thereby resulting in high viscosity. However, this increase is affected at elevated operating temperature as the viscosity difference shrinks simultaneously with temperature. As earlier discussed in the case of thermal conductivity, Brownian motion of nanoparticle is enhanced with an increase in temperature, which has an influence on viscosity, mostly a decrease in its value. This is due to breaking down of both the amino acids of protein-which are denatured at high temperature-and sugars of starch molecules, which build a layer on the nanoparticles.

$2 \mathrm{E} 1 \mathrm{H}$ is a less volatile solvent and solubilises poorly in water. For this reason, it forms layers on the nanofluid, between the walls of the container or pipe and the nanofluid, and between nanoparticles and the nanofluid when added directly. This increases the friction between the fluid and the pipe or container, thus, increasing the force required to pump or stir the fluid. This implies an increasing pressure difference between both ends of the tube. When the temperature is increased, this insoluble solvent layer begins to expand, meaning the layer shrinks out in thickness and diffuses into the fluid thereby reducing the viscosity as shear rate increases as expected.

This phenomenon of GA deposition on ANPs is avoided when the nanoparticles are surface functionalised prior to their dispersion into the base fluid. Since $2 \mathrm{E} 1 \mathrm{H}$ is poorly soluble in water, it remains adsorbed on ANPs surfaces even after been dispersed in the base fluid, hence, denying any direct deposition of GA on the nanoparticles. This justifies why SFM sample recorded a lower dynamic viscosity than conventional method sample.

Figure 11 reveals the dynamic viscosity enhancement due to addition of HTA and surface functionalisation of ANPs. An average increase in dynamic viscosity of $7 \%$ at low temperature and $6 \%$ at high temperature was recorded for $\mathrm{LANF}+\mathrm{HTA}+\mathrm{CM}$ sample when compared to LANF without HTA. Similarly, for LANF + HTA + SF sample, an increase in viscosity was observed between 2.4 and $1.1 \%$ at low and high temperature respectively when compared to LANF without HTA sample. However, for LANF + HTA + SF sample, the viscosity decreased by about $5 \%$ when compared to the corresponding sample prepared by conventional procedure $(\mathrm{LANF}+\mathrm{HTA}+\mathrm{CM})$.

\subsection{The Mouromtseff number (Mo)}

At the early stage of nanofluid research on some of the properties such as thermal conductivity and viscosity, there has been ambiguity over the estimation of efficiency of a given nanofluid due to the inverse variation between these two most significant properties. This has become significantly important for researchers to develop a comprehensive model that could help evaluate nanofluid efficiency for heat transfer accurately. Years later, Mouromtseff I. came up with what was later known as Mouromtseff number denoted by $M o$ [57]. The number, $M o$, is described as a quantity of merit, which is based on the most important fluid properties such as heat capacity $(\mathrm{Cp})$, thermal conductivity $(\lambda)$, density $(\rho)$ and
Fig. 11 Calculated results of dynamic viscosity enhancement (\%) of samples against temperature $(\mathrm{K})$. Where En-HTA + SF is enhancement due to HTA addition and surface functionalisation; En-HTA is enhancement due to HTA addition; and En-SF is enhancement due to surface functionalisation

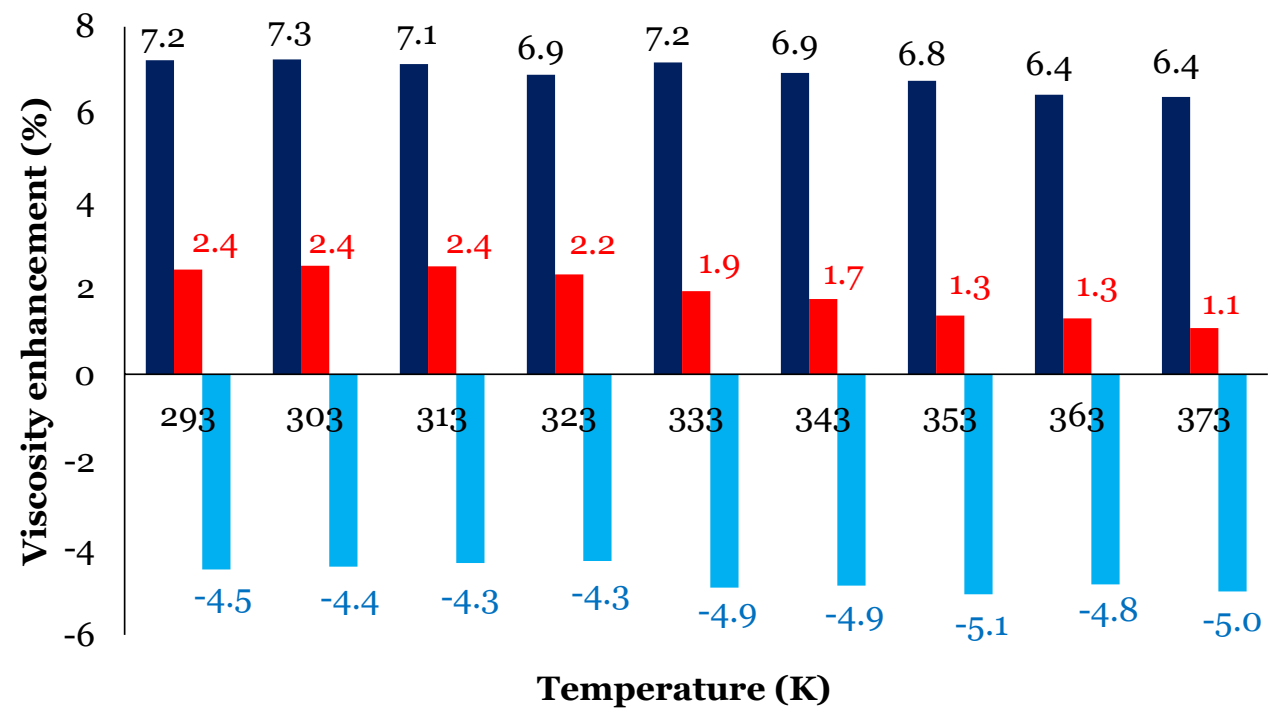


viscosity $(\mu)$. It was reported that thermal fluid with high capability of heat transfer results in high $M o$ value, while fluids with low Mo value have shown low capability of heat transfer $[36,51]$ and vice versa.

$\frac{M o_{n f}}{M o_{b f}}=\frac{\lambda_{n f}}{\lambda_{b f}}$

According to Bobbo et al. [58], Eq. 4 holds for an internal laminar flow and that the Mo value is both concentrationand temperature-dependent. It can only be found experimentally whether the ratio is greater than 1 or not. Ratios greater than 1 indicates the nanofluid have greater capability of heat transfer since the internal flow is laminar.

Mo $=\frac{\rho^{0.8} \lambda^{0.67} \boldsymbol{c p ^ { 0 . 3 3 }}}{\boldsymbol{\mu}^{0.47}}$

On the other hand, Eq. 5 holds for an internal turbulent flow evaluation of nanofluid for heat transfer capability. In technological applications, the turbulent flow evaluation is significantly critical because it is the nature of flow mostly encountered. Nanofluids with $M o$ values lower than 1 are not considered good for heat transfer applications. However, this also depends on the concentration and temperature at which the value was obtained, since it is also a concentration and temperature-dependent.

Figure 12 shows the temperature dependency of Mouromtseff number $(\mathrm{Mo})$. As one may observe, both LANF samples prepared with HTA gives rise to a $M o$ value greater than 1 at a temperature of $333 \mathrm{~K}$, which is an indicator of its heat transfer capability. According to both Bouguerra et al. [38] and Bobbo et al. [58], fluids with Mo value $>1$ have been experimentally proven to have high heat transfer capability. Thus, the analysis of Mo values at different temperatures had established that LANF with HTA exhibits good heat transfer property at a temperature below the usual vapour generator temperature of $346 \mathrm{~K}$ to $368 \mathrm{~K}$, which is a prerequisite for thermal applications. However, the LANF+ HTA + SF sample has a 5\% enhancement of $M o$ value when compared to the LANF + HTA + CM sample prepared by the conventional method.

\subsection{Conclusion}

This paper developed a particle surface functionalisation method different from those presented by Lee et al. [11], Yarmand et al. [21] and others [22-25]. Considering the surface chemistry of nanoparticles, surfactant nature and the interaction between aqueous $\mathrm{LiBr}$ solution and nanoparticles, alumina nanoparticles were first functionalised with $2 \mathrm{E} 1 \mathrm{H}$ to reduce the surface energy between the particles and the base fluid. The base fluid was also treated with GA to enhance dispersion stability. The dispersion of the functionalised alumina nanoparticles was followed by magnetic stirring $30 \mathrm{~min}$ and ultrasonication for $2 \mathrm{~h}$ and $30 \mathrm{~min}$. This is contrary to the procedures presented by refs. [20, 22, 24, $25,28,31]$, which reported higher magnetic stirring and ultrasonication time of more than $30 \mathrm{~min}$ and $21 / 2 \mathrm{~h}$ respectively. After the characterisation of the LANF, the following conclusions were reached:

Both samples prepared with HTA show good stability compared sample prepared without HTA as presented in
Fig. 12 Calculated results of Mouromtseff Number $(\mathrm{Mo})$ against temperature using Eq. 5 for LANF sample without HTA, LANF with HTA prepared by conventional method (CM) and LANF with HTA prepared by surface functionalisation method (SFM)
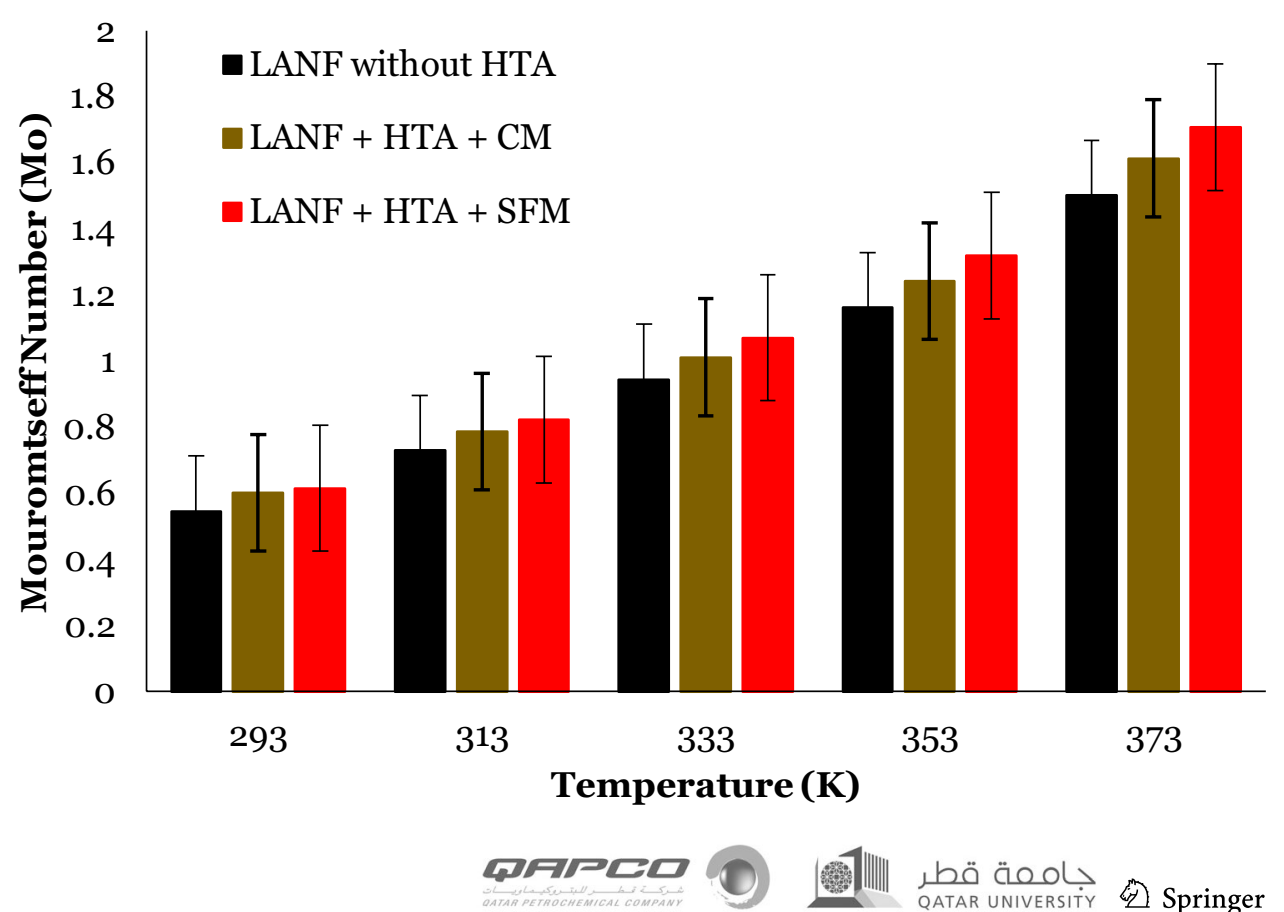
Fig. 3, which is in agreement with reports from Lee et al. [11, 21-24, 26-28].

LANF prepared with HTA using the developed surface functionalisation method produces a fluid with high particle concentration distribution in the base fluid, which was not measured by other researchers who used a similar method. The method recorded $22.7 \%$ enhancement in particle concentration distribution compared to the sample prepared by a conventional method.

The method improves the thermal conductivity of the fluid. An enhancement of $3 \%$ was recorded using the new method compared to the conventional method.

The surface functionalisation method can improve the dynamic viscosity of the nanofluid. A reduction of 5\% in dynamic viscosity was obtained in this study. This is contrary to the reported studies [48-55].

Salt-based binary nanofluid prepared by surface functionalisation method has a higher heat transfer capability than that prepared by a conventional method as presented in Fig. 12.

Acknowledgements The authors wish to express their sincere gratitude to EPSRC and Innovate UK for the financial support received to carry out this work under research grant 132401 (I-UK) and EP/P016316/1. In addition, M. Umar personally wishes to thank the Petroleum Technology Development Fund (PTDF) for sponsoring his $\mathrm{PhD}$ programme.

\section{Declarations}

Conflict of interest The authors declare no competing interests.

Open Access This article is licensed under a Creative Commons Attribution 4.0 International License, which permits use, sharing, adaptation, distribution and reproduction in any medium or format, as long as you give appropriate credit to the original author(s) and the source, provide a link to the Creative Commons licence, and indicate if changes were made. The images or other third party material in this article are included in the article's Creative Commons licence, unless indicated otherwise in a credit line to the material. If material is not included in the article's Creative Commons licence and your intended use is not permitted by statutory regulation or exceeds the permitted use, you will need to obtain permission directly from the copyright holder. To view a copy of this licence, visit http://creativecommons.org/licenses/by/4.0/.

\section{References}

1. M. Sheikholeslami, S.A. Farshad, Z. Ebrahimpour, Z. Said, Recent progress on flat plate solar collectors and photovoltaic systems in the presence of nanofluid: a review. J. Clean. Prod. 293, 126119 (2021). https://doi.org/10.1016/j.jclepro.2021.126119

2. Z. Said, A. Ahmed, A. Hachicha, B. Sadegh, A. Yousef, S.A. Taha, E.B. Enas, Recent advances on nanofluids for low to medium temperature solar collectors: energy, exergy, economic analysis and environmental impact. Prog. Energy Combust. Sci. 84, 100898 (2021). https://doi.org/10.1016/j.pecs.2020.100898
3. M. Sheikholeslami, S.A. Farshad, Z. Ebrahimpour, Z. Said, Analyzing entropy and thermal behaviour of nanomaterial through solar collector involving new tapes. Int. Commun. Heat Mass Transfer 123, 105190 (2021). https://doi.org/10.1016/j.icheatmass transfer.2021.105190

4. Z. Said, M.A. Sabiha, R. Saidur, A. Hepbasli, N.A. Rahim, S. Mekhilef, T.A. Ward, Performance enhancement of a flat plate solar collector using titanium dioxide nanofluid and polyethylene glycol dispersant. J. Clean. Prod. 92, 343-353 (2015)

5. Z. Said, R. Saidur, M.A. Sabiha, N.A. Rahim, M.R. Anisur, Thermo-physical properties of single wall carbon nanotubes and its effect on exergy efficiency of a flat plate solar collector. Sol. Energy 115, 757-769 (2015)

6. L.S. Sundar, M.K. Singh, V. Punnaiah, A.C.M. Sousa, Experimental investigation of A12O3/water nanofluids on the effectiveness of solar flat-plate collectors with and without twisted tape inserts. Renew. Energy 119, 820-833 (2018)

7. M. Sheikholeslami, S.A. Farshad, Investigation of solar collector system with turbulator considering hybrid nanoparticles. Renewable Energy 171, 1128-1158 (2021). https://doi.org/10.1016/j. renene.2021.02.137

8. C. Stanciu, D. Stanciu, A.T. Gheorghian, Thermal analysis of a solar powered absorption cooling system with fully mixed thermal storage at startup. Energies 10, 72 (2017). https://doi.org/10.3390/ en10010072

9. S.M. Xu, X.D. Huang, R. Du, An investigation of the solar powered absorption refrigeration system with advanced energy storage technology. Sol. Energy 85, 1794-1804 (2011). https://doi.org/10. 1016/j.solener.2011.04.022

10. D.A. Selvaraj, K. Victor, Design and performance of solar PV integrated domestic vapour absorption refrigeration system, Int J Photoenergy, 2021, 6655113, 10, (2021). https://doi.org/10.1155/ 2021/6655113

11. J.K. Lee, H. Kim, M.H. Kim, J. Koo, Y.T. Kang, The effect of additives and nanoparticles on falling film absorption performance of binary nanofluids $(\mathrm{H} 2 \mathrm{O} / \mathrm{LiBr}+$ Nanoparticles $)$. J. Nanosci. Nanotechnol. 9, 7456-7460 (2009). https://doi.org/10.1166/jnn. 2009.1790

12. A. Zeiny, M.A. Haruna, D. Wen. Aqueous lithium bromide nanosolution for solar absorption refrigeration systems. Technologies and Materials for Renewable Energy, Environment and Sustainability, AIP Conf. Proc. 2123, 020083-1-020083-11; https://doi. org/10.1063/1.5117010

13. M.A. Alazwari, M.R. Safaei, Combination effect of baffle arrangement and hybrid nanofluid on thermal performance of a shell and tube heat exchanger using 3-D homogeneous mixture model. Mathematics 9, 881 (2021). https://doi.org/10.3390/math9080881

14. Z. Tian, H. Arasteh, A. Parsian, A. Karimipour, M.R. Safaei, T.K. Nguyen, Estimate the shear rate \& apparent viscosity of multiphased non-Newtonian hybrid nanofluids via new developed support vector machine method coupled with sensitivity analysis. Phys. A 535, 122456 (2019). https://doi.org/10.1016/j.physa.2019. 122456

15. A. Karimipour, S.A. Bagherzadeh, A. Taghipour, A. Abdollahi, M.R. Safaei, A novel non-linear regression model of SVR as a substitute for ANN to predict conductivity of MWCNT-CuO/ water hybrid nanofluid based on empirical data. Phys. A 521, 89-97 (2019). https://doi.org/10.1016/j.physa.2019.01.055

16. M. Afrand, K.N. Najafabadi, N. Sina, M.R. Safaei, ASh. Kherbeet, S. Wongwises, M. Dahari, Prediction of dynamic viscosity of a hybrid nano-lubricant by an optimal artificial neural network. Int. Commun. Heat Mass Transfer 76, 209-214 (2016). https://doi.org/ 10.1016/j.icheatmasstransfer.2016.05.023

17. M.R. Safaei, A. Hajizadeh, M. Afrand, C. Qi, H. Yarmand, N.W.B.M. Zulkifli, Evaluating the effect of temperature and concentration on the thermal conductivity of $\mathrm{ZnO}-\mathrm{TiO} 2 / \mathrm{EG}$ 
hybrid nanofluid using artificial neural network and curve fitting on experimental data. Phys. A (2018). https://doi.org/10.1016/j. physa.2018.12.010

18. A. Malvandi, M.R. Safaei, M.H. Kaffash, D.D. Ganji, MHD mixed convection in vertical annulus filled with $\mathrm{Al} 2 \mathrm{O} 3$-water nanofluid considering nanoparticles migration. J. Magn. Magn. Mater. 382, 296-306 (2015). https://doi.org/10.1016/j.jmmm.2015.01.060

19. O.A. Akbari, D. Toghraie, A. Karimipour, M.R. Safaei, M. Goodarzi, H. Alipour, M. Dahari, Investigation of rib's height effect on heat transfer and flow parameters of laminar water$\mathrm{Al}_{2} \mathrm{O}_{3}$ nanofluid in a rib-microchannel. Appl. Math. Comput. 290, 135-153 (2016). https://doi.org/10.1016/j.amc.2016.05.053

20. A. Karimipour, S.A. Bagherzadeh, M. Goodarzi, A.A. Alnaqi, M. Bahiraei, M.R. Safaei, M.S. Shadloo, Synthesized CuFe2O4/SiO2 nanocomposites added to water/EG: Evaluation of the thermophysical properties beside sensitivity analysis and EANN. Int. J. Heat Mass Transf. 127, 1169-1179 (2018)

21. H. Yarmand, S. Gharehkhania, S.F.S. Shirazi, M. Goodarzi, A. Amiria, W.S. Sarsama, M.S. Alehashemd, M. Dahari, S.N. Kazi, Study of synthesis, stability and thermo-physical properties of graphene nanoplatelet/platinum hybrid nanofluid. Int. Commun. Heat Mass Transfer 77, 15-21 (2016). https://doi.org/10.1016/j. icheatmasstransfer.2016.07.010

22. W.I. Liu, O. Malekahmadi, S.A. Bagherzadeh, M. Ghashang, A. Karimipoure, S. Hasanib, I. Tlilie, M. Goodarzig, A novel comprehensive experimental study concerned graphene oxide nanoparticles dispersed in water: synthesise, characterisation, thermal conductivity measurement and present a new approach of RLSF neural network. Int. Commun. Heat Mass Transfer 109, 104333 (2019). https://doi.org/10.1016/j.icheatmasstrans fer.2019.104333

23. P.P.C. Sartoratto, A.V.S. Neto, E.C.D. Lima, Preparation and electrical properties of oil-based magnetic fluids. J. Appl. Phys. 97, 10Q917 (2005)

24. A. Shahsavar, S. Khanmohammadi, A. Karimipour, M. Goodarzi, A novel comprehensive experimental study concerned synthesizes and prepare liquid paraffin-Fe3O4 mixture to develop models for both thermal conductivity \& viscosity: a new approach of GMDH type of neural network. Int. J. Heat Mass Transf. 131, 432-441 (2019). https://doi.org/10.1016/j. ijheatmasstransfer.2018.11.069

25. M. Goodarzi, D. Toghraie, M. Reiszadeh, M. Afrand, Experimental evaluation of dynamic viscosity of ZnO-MWCNTs/ engine oil hybrid nano-lubricant based on changes in temperature and concentration. J. Therm. Anal. Calorim. (2018). https:// doi.org/10.1007/s10973-018-7707-8

26. H. Yarmand, S. Gharehkhani, G. Ahmadi, S.F. Seyed Shirazi, S. Baradaran, E. Montazer, M.N.M. Zubir, M.S. Alehashem, S.N. Kazi, M. Dahari, Graphene nanoplatelets-silver hybrid nanofluids for enhanced heat transfer, Energy Conversion and Management, 100, pp. 419-428 (2015).

27. M. Bahiraei, M. Jamshidmofid, M. Goodarzi, Efficacy of a hybrid nanofluid in a new microchannel heat sink equipped with both secondary channels and ribs. J. Mol. Liq. (2018). https:// doi.org/10.1016/j.molliq.2018.10.003

28. S.O. Giwa, M. Sharifpur, M. Goodarzi, H. Alsulami, J.P. Meyer, Influence of base fluid, temperature, and concentration on the thermo-physical properties of hybrid nanofluids of alumina-ferrofluid: experimental data, modelling through enhanced ANN, ANFIS, and curve fitting. J. Therm. Anal. Calorim. (2020). https://doi.org/10.1007/s10973-020-09372-w

29. Z.S. Lu, R.Z. Wang, Experimental performance investigation of small solar air-conditioning systems with different kinds of collectors and chillers. Sol. Energy 110, 7-14 (2014)

30. J. Duffie, W. Beckman, Solar Engineering of Thermal Processes (John Wiley \& Sons Inc., Hoboken, NJ, USA, 2006)
31. N.A. Che Sidik, H.A. Mohammed, O.A. Alawi, S. Samion. A review on preparation methods and challenges of nanofluids, International Communications in Heat and Mass Transfer, 54, pp. 115-25 (2014). https://doi.org/10.1016/j.icheatmasstransfer.2014.03.002

32. I. Mahbubul, R. Saidur, M. Amalina, M. Niza, Influence of ultra-sonication duration on rheological properties of nanofluid: an experimental study with alumina-water nanofluid. Int. Commun. Heat Mass Transf. 76, 33-40 (2016)

33. S. Lee, S.U.S. Choi, S. Li, J.A. Eastman, Measuring thermal conductivity of fluids containing oxide nanoparticles. Transactions of the ASME. J. Heat Transfer 121, 280-289 (1999)

34. X. Wang, X. Xu, S.U.S. Choi, Thermal conductivity of nanoparticle-fluid mixture. J. Thermophys. Heat Transfer 13, 474-480 (1999)

35. J.A. Eastman, S.U.S. Choi, S. Li, L.J. Thompson, S. Lee, Enhanced thermal conductivity through the development of nanofluids, Materials Research Society Symposium - Proceedings. Materials Research Society, Pittsburgh, PA, USA, Boston, MA, USA 457, 3-11 (1997)

36. N. Bouguerra, A. Khabou, S. Poncet, S. Elkoun. Thermal conductivity of $\mathrm{Al}_{2} \mathrm{O}_{3}$ /water-based nanofluids: revisiting the influences of $\mathrm{pH}$ and surfactant, Int. Sch. Sci. Res. Innov. 10(12), 1849-1858 (2016). scholar.waset.org/1999.8/10006067

37. L.A. Defrate, A.E. Hoerl. Optimum design of ejectors using digital computers, Chemical Engineering Symposium Series No. 21 American Institute of Chemical Engineers (1959).

38. N. Bouguerra, S. Poncet, S. Elkoun, Dispersion regimes in alumina/water-based nanofluids: simultaneous measurements of thermal conductivity and dynamic viscosity. Int. Commun. Heat Mass Transfer 92, 51-55 (2018)

39. https://www.malvernpanalytical.com/en/products/product-range/ nanosight-range/nanosight-ns300 Accessed on 19th November 2018.

40. F. Mashali, E.M. Languri, J. Davidson, D. Kerns, W. Johnson, K. Nawaz, G. Cunningham, Thermo-physical properties of diamond nanofluids: a review. Int. J. Heat Mass Transf. 129, 1123-1135 (2019)

41. J.K. Horrocks, E. McLaughlin. Non-steady-state measurements of the thermal conductivities of liquid polyphenyls, Proc. R Soc. A Math. Phys. Eng. Sci. 273, pp. 259-274 (1963). https://doi.org/ 10.1098/rspa.1963.0087

42. J.J. Healy, J.J. De Groot, J. Kestin. The theory of the transient hot-wire method for measuring thermal conductivity, Phys. B+C. 82, pp. 392-408 (1976). https://doi.org/10.1016/0378-4363(76) 90203-5

43. X. Zhang, M. Fujii, Simultaneous measurements of the thermal conductivity and thermal diffusivity of molten salts with a transient short-hot-wire method. Int. J. Thermophys. 21, 71-84 (2000). https://doi.org/10.1023/a:1006604820755

44. http://www.jumbo.th.com/application.html Accessed 16th March 2019.

45. T.P. Teng, Y.H. Hung, T.C. Teng, H.E. Mo, H.G. Hsu, The effect of alumina/water nanofluid particle size on thermal conductivity. Appl. Therm. Eng. 30, 2213-2218 (2010)

46. F. Jabbari, A. Rajabpour, S. Saedodin, Thermal conductivity and viscosity of nanofluids: a review of recent molecular dynamics studies. Chem. Eng. Sci. 174, 67-81 (2017)

47. J. Philip, P.D. Shima, Thermal properties of nanofluids. Adv. Coll. Interface. Sci. 183-184, 30-45 (2012)

48. W.Q. Lu, Q.M. Fan, Study for the particle's scale effect on some thermo-physical properties of nanofluids by a simplified molecular dynamics method. Eng. Anal. Boundary Elem. 32(4), 282-289 (2008)

49. R.V. Ya, S.L. Krasnolutskii, Dependence of the viscosity of nanofluids on nanoparticle size and material. Phys. Lett. 378(26-27), $1-8(2014)$

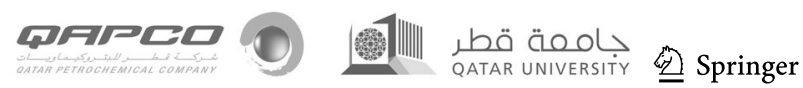


50. V.Y. Rudyak, S.L. Krasnolutskii, Simulation of the nanofluid viscosity coefficient by the molecular dynamics method. Tech. Phys. 60(6), 798-804 (2015)

51. Z. Lou, M. Yang, Molecular dynamics simulations on the shear viscosity of Al2o3 nanofluids. Comput. Fluids 117, 17-23 (2015)

52. L. Gui, D. Yuan-Yuan, W. Xiao-Dong, Surface tension, viscosity, and rheology of water-based nanofluids: a microscopic interpretation on the molecular level. J. Nanopart. Res. 16(2564), 1-11 (2014)

53. V.Y. Rudyak, S.L. Krasnolutskii. The inter action potential of dispersed particles with carrier gas molecules. In: Proceedings of the 21 st International Symposium on Rarefied Gas Dynamics, 1, pp. 263-70 (1999).

54. V.Y. Rudyak, S.L. Krasnolutskii, Kinetic description of nanoparticle diffusion in rarefied gas. Doklady Phys. 46(12), 897-899 (2001)
55. R.T. Cygan, J.J. Liang, A.G. Kalinichev, Molecular models of hydroxide, oxyhydroxide, and clay phases and the development of a general force field. J. Phys. Chem. B 108(4), 1255-1266 (2004)

56. E.M.I. Elzain, L. Mobarak, M. Dirar, Investigating the electric conductivity, magnetic inductivity, and optical properties of Gum Arabic crystals. J Basic Appl Chem 2(6), 35-49 (2012)

57. I. Mouromtseff, Water and forced-air cooling of vacuum tubes non-electronic problems in electronic tubes. Proc. Inst. Radio Eng. 30(4), 190-205 (1942)

58. S. Bobbo, L. Colla, M. Scattolini, F. Agresti, S. Barison, C. Pagura, L. Fedele. Thermal conductivity and viscosity measurements of water-based silica nanofluids, NSTI-Nanotech 2011, www.nsti.org. ISBN 978-1-4398-7139-3 Vol. 2, pp. 478-81 (2011). 